\title{
Glueing of fundal varices
}

\author{
Nasim Mahmoudi MD, J Scott Whittaker BSc MD FRCPC
}

G astric variceal bleeding is an uncommon, serious compli-

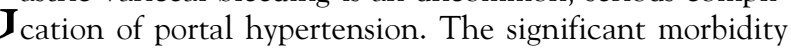
and mortality resulting from bleeding from gastric varices presents a challenge for gastroenterologists. The management of this complication has not been standardized. Although transjugular intrahepatic portosystemic shunt (TIPS) is used in many centres to treat gastric varices, endoscopic treatment with the tissue glue cyanoacrylate (N-butyl-2. cyanoacrylate) has been used successfully in many countries for 20 years and is considered, by many clinicians, to be the optimal initial treatment for bleeding gastric varices (1). Despite the widespread use of cyanoacrylate, there are still controversies in the literature regarding its use. The present article deals with the indications, technique, preparation, catheter use, long-term results and cost-effectiveness of the procedure. Close attention to these recommendations can result in successful and safe usage of the tissue glue.

The endoscopy unit planning to perform gastric variceal glueing should have a detailed nursing protocol established before performing this procedure.

\section{GLUE: WHAT IS IT?}

The tissue glue, N-butyl-2-cyanoacrylate, is a watery solution that polymerizes and hardens within $20 \mathrm{~s}$ in a physiological milieu and instantaneously on contact with blood. Because the rapid solidification of the glue makes endoscopic application technically difficult, it is necessary to dilute it with the oily contrast agent Lipiodol Ultra Fluid (Therapex, Canada). A 50/50 mixture of Histoacryl (B. Braun Melsungen AG, Germany) and Lipiodol is used for injection.

Patients with allergies to iodine should not receive this therapy because Lipiodol is an iodized oil emulsion.

\section{METHOD}

\section{Preparation}

During an active variceal bleed, an endoscope with a $6 \mathrm{~mm}$ working channel is preferred to adequately suction blood. For the glue injection itself, a therapeutic endoscope with a $3.7 \mathrm{~mm}$ working channel is preferred to allow for accurate control of the injector catheter (a standard gastroscope with a $3.2 \mathrm{~mm}$ channel often does not allow the injection catheter to pass when the gastroscope is retroflexed in the stomach). For the treatment of gastric varices, two well-trained endoscopy assistants are needed.

We use the Marcon-Haber MH-1-240 (Wilson-Cook Medical

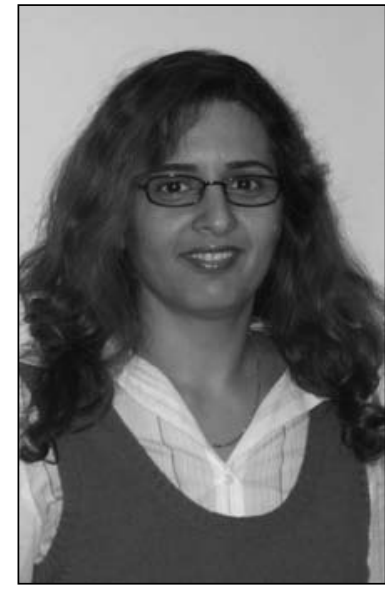

Dr Nasim Mahmoudi

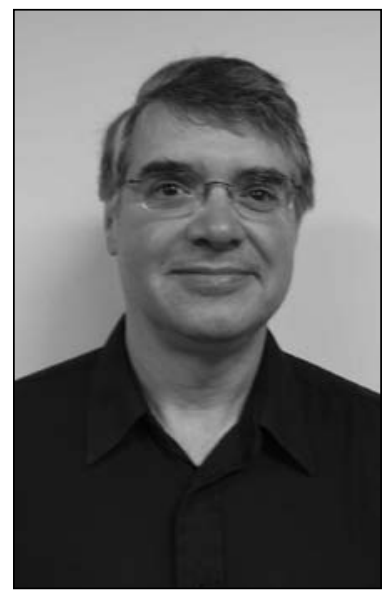

Dr J Scott Whittaker Inc, USA) injection catheter (23 gauge needle, $7 \mathrm{Fr}$ and $240 \mathrm{~cm}$ ) for glue injection. The injection needle should be checked before use with the endoscope in a retroflexed position to ensure that the needle can be brought out and withdrawn completely within the patient. At least three catheters need to be available because the catheters may become clogged with glue and need to be replaced.

Before using any specific injection catheter, distilled water should be injected into the catheter with the precise amount of dead space determined (the dead space is approximately $0.8 \mathrm{~mm}$ in many catheters, but needs to be determined empirically). This is important so that after the glue has been injected into the varix with the syringe, the syringe is flushed with the precise amount of fluid (but not more) to empty the catheter of the glue.

While working with Histoacryl, all personnel need to wear gloves and goggles. The patient's eyes are protected with a towel over the forehead and eyes.

We normally prepare a minimum of three $2 \mathrm{~mL}$ syringes containing a mixture of $0.5 \mathrm{~mL}$ Histoacryl and $0.5 \mathrm{~mL}$ Lipiodol. The catheter is primed with Lipiodol, the syringe of Lipiodol is then removed and the $2 \mathrm{~mL}$ Histoacryl/Lipiodol syringe is attached to the injector catheter. A volume equal to approximately two-thirds of the dead space of the catheter is then injected into the catheter.

Injection technique

Lipiodol or silicone oil is applied to the open biopsy port. The gastroscope is placed in a retroflexed position juxtaposed to the varix in preparation for injection and the suction is turned off. The previously prepared catheter is inserted into the biopsy channel, and observed endoscopically. The catheter, with the needle still withdrawn, is advanced without variceal contact to ensure that the direction of the insertion leads to an appropriate site of potential injection into the varix. The needle is then pushed out and placed directly into the gastric varix. The catheter is injected with the remainder of the Histoacryl/Lipiodol mixture followed by an injection of either Lipiodol or water (but not

Division of Gastroenterology, Department of Medicine, University of British Columbia, Vancouver, British Columbia

Correspondence and reprints: Dr J Scott Whittaker, 770-1190 Hornby Street, Vancouver, British Columbia V62 2K5. Telephone 604-688-6332 ext 226, fax604-689-2004, e-mail swhittaker@telus.net 


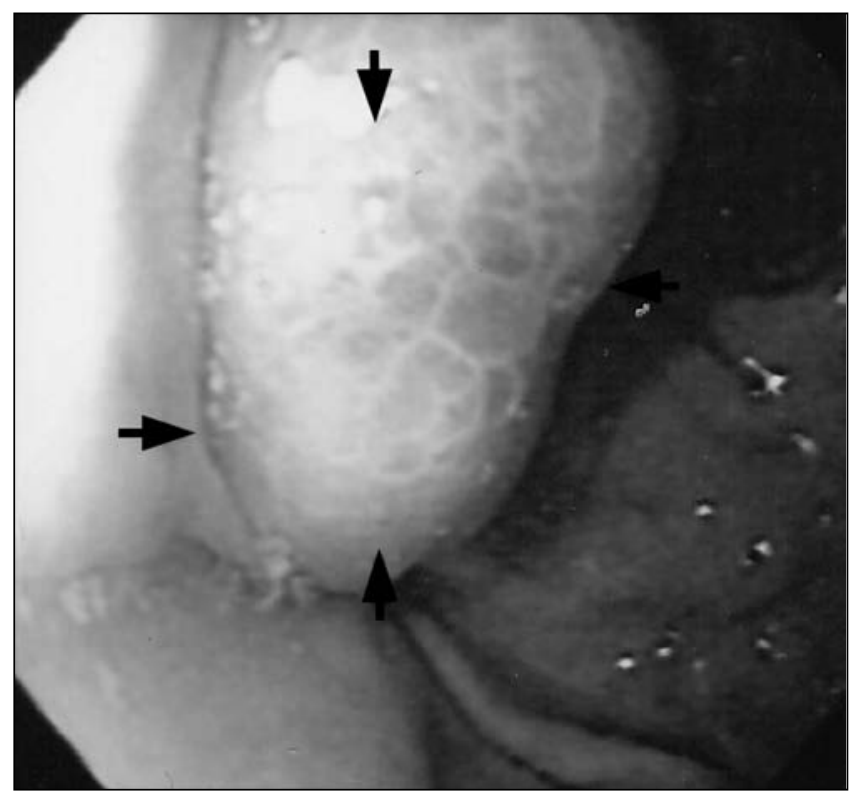

Figure 1) Gastric varix

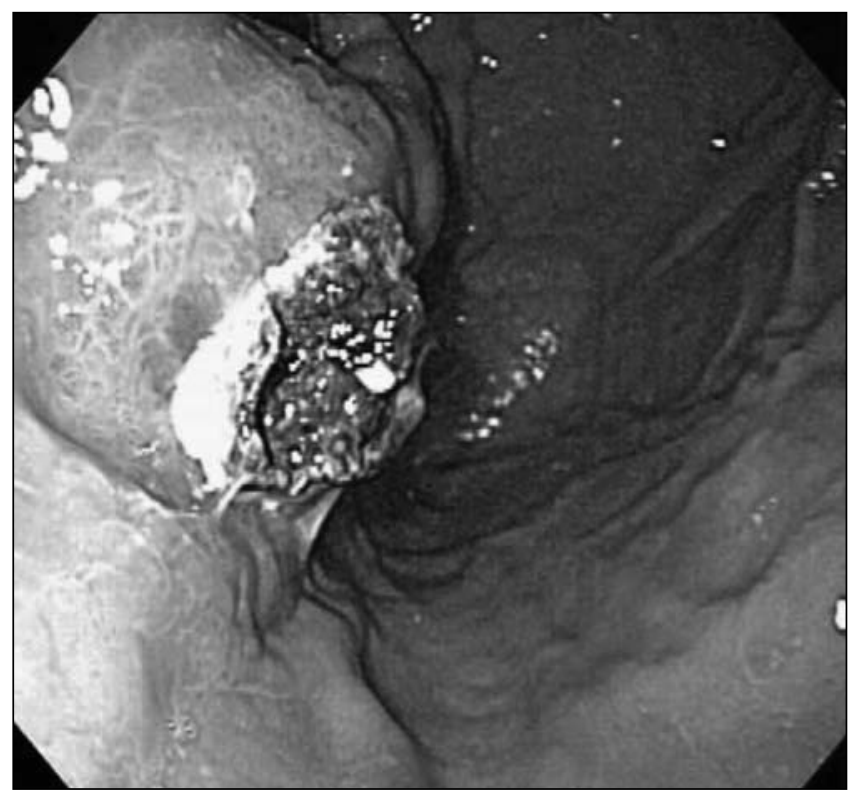

Figure 3) Ulcer in varix several days postinjection

saline, which causes polymerization of the glue) equal to the dead space of the catheter to clear the rest of the glue. We have tended to use Lipiodol for flushing, but water is less viscous and therefore easier to push. After the endoscopy assistant informs the endoscopist that the flush has been completed, the catheter is withdrawn from the varix with the needle still out and the catheter is continually flushed with water (or Lipiodol) until another injection of glue is needed. The endoscopist continually insufflates the stomach with air. If no further injections are thought to be needed, an attempt is made to withdraw the needle back into the sheath. If successful, the catheter can be used to palpate the injected varix (or varices) to ensure it is hard. If the varix is soft, further injections are needed. For further injections, fill the injection catheter

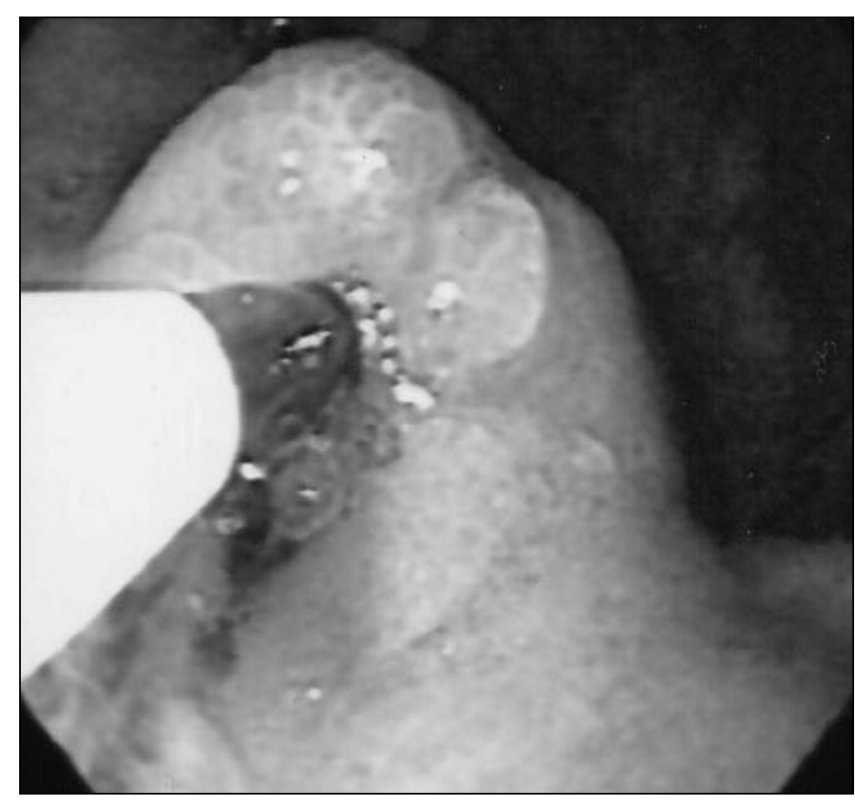

Figure 2) Needle in gastric varix

with the Histoacryl/Lipiodol mixture, using two-thirds the volume of the dead space. Insert the injection needle into the varix and complete the injection with the Histoacryl/Lipiodol mixture. This is followed by flushing with water using a volume of the dead space of the catheter, then withdraw the catheter as before and continue to flush the catheter with water once the catheter has been removed from the varix (Figures 1, 2 and 3).

If the needle cannot be retracted into the catheter, the catheter is removed via the biopsy channel and a new catheter is used.

It is important to inject no more than $1 \mathrm{~mL}$ of Histoacryl/Lipiodol at a time to avoid embolization. However, several separate injections can be made into one varix in one sitting.

Not infrequently, withdrawal of the catheter from the varix leads to a temporary rush of blood and glue from the injection site. Some endoscopists prefer, therefore, to leave the catheter in the varix for up to $20 \mathrm{~s}$ to ensure there has been adequate polymerization of the blood/glue mixture. We prefer to pull the catheter out of the varix immediately after injection. Prolonged waiting can lead to the needle sticking in the varix.

\section{COMPLICATIONS}

Tissue necrosis may occur due to paravariceal injection, which may lead to deep ulceration and occasional perforation. Paravariceal injection can also cause early rebleeding if the varix is not completely obliterated.

Embolism is another rare but potentially serious complication. Emboli may go to the lung $(2,3)$ but systemic (arterial) embolization has also occurred (4). An important cause of increased risk of embolism during procedure is instillation of more than $1 \mathrm{~mL}$ of the Histoacryl/Lipiodol mixture per injection.

Portal and splenic vein thrombosis presenting with severe abdominal pain starting $30 \mathrm{~min}$ after glue injection has been reported (5).

Other immediate complications include fever, impaction of the injected needle and early rebleeding at three to four days after injection due to necrosis around the site of injection. 
Adherence of glue to the endoscope can be prevented by keeping the tip of the endoscope at a safe distance from the site of injection and constant insufflation of air during the injection. If the glue sticks to the lens during procedure, the endoscope should be withdrawn and immediately cleaned with ethanol to prevent damage to the instrument.

\section{Follow-up}

Three or four days after injection, a repeat endoscopy is performed to determine whether there has been complete obliteration of the gastric varices. The varices can be tested using closed biopsy forceps or an injection catheter. Although follow-up endoscopy every three to six months has been recommended, it has not been routinely performed.

\section{COST-EFFECTIVENESS}

There are few studies evaluating cost-effectiveness of cyanoacrylate glue injection. A recent retrospective review (1) compared bleeding gastric varices treated either by TIPS or cyanoacrylate glue injection. Economic analysis was based on the direct costs for a fixed financial year. The initial stay was shorter in the glue group $(13 \pm 1$ days versus $18 \pm 2$ days; $\mathrm{P}=0.05)$, but there was no difference in the overall mortality rate. The median cost within six months of initial gastric variceal bleeding was $\$ 4,138$ for glue versus $\$ 11,906$ for TIPS treatment $(\mathrm{P}<0.0001)$.

\section{REFERENCES}

1. Mahadeva S, Bellamy MC, Kessel D, Davies MH, Millson CE. Cost-effectiveness of $N$-butyl-2-cyanoacrylate (histoacryl) glue injections versus transjugular intrahepatic portosystemic shunt in the management of acute gastric variceal bleeding. Am J Gastroenterol 2003;98:2688-93.

2. Alexander S, Korman MG, Sievert W. Cyanoacrylate in the treatment of gastric varices complicated by multiple pulmonary emboli. Intern Med J 2006;36:462-5.

3. Rickman OB, Utz JP, Aughenbaugh GL, Gostout CJ. Pulmonary embolization of 2-octyl cyanoacrylate after endoscopic injection therapy for gastric variceal bleeding. Mayo Clin Proc 2004;79:1455-8

\section{DISCUSSION}

Early rebleeding is mainly due to incomplete obliteration of the varices. In the first randomized trial (6) comparing cyanoacrylate with band ligation in the management of bleeding gastric varices, the rate of primary hemostasis was $87 \%$ versus $45 \%$, respectively. In the experience of Gotlib (7), primary hemostasis following glue injection was achieved in almost all cases and early rebleeding rate was $2.2 \%$. The division of gastroenterology at the University of British Columbia (Vancouver, British Columbia) studied all patients with bleeding gastric varices presenting to St Paul's Hospital (Vancouver, British Columbia) and Vancouver General Hospital in British Columbia from 2001 to 2005 . Of the 37 patients studied, acute hemostasis was achieved in $97.3 \%$ of patients. The amount of Histoacryl glue was less than $5 \mathrm{~mL}$ in $97.3 \%$ of patients. Early rebleeding occured in $2.7 \%$ and late rebleeding occured in another $2.7 \%$ of patients. Median follow-up was 21 months with a mortality rate of $24.3 \%$, of which $2.7 \%$ was due to bleeding. There were no injection-related complications in their study. A preliminary report describing the first 18 patients evaluated has been published (8)

Most of the risks of cyanoacrylate are preventable. Proper preparation, experienced nursing staff and standardized injection technique may help in minimizing the risk of complications and improve the long-term outcome of bleeding gastric varices.

4. Roesch W, Rexroth G. Pulmonary, cerebral and coronary emboli during bucrylate injection of bleeding fundic varices. Endoscopy 1998;30:S89-90.

5. Al Hamad A, Kabbani A, Al Kadhi Y. N-butyl-2-cyanoacrylate (Histoacryl) complication: A case report. Ann Saudi Med 2006;26:71-2.

6. Soehendra N, Grimm H, Maydeo A, et al. Endoscopic obliteration of fundal varices. Can J Gastroenterol 1990;4:643-6.

7. Gotlib JF. Endoscopic obturation of esophageal and gastric varices with a cyanoacrylate tissue adhesive. Can J Gastroenterol 1990;9:637-8.

8. Al Ali J, Byrne M, Cheung J, Whittaker, S, Steinbrecher U, Enns R. Management of bleeding gastric varices with Histoacryl glue injection Long-term outcomes. Can J Gastroenterol 2006;20:89A-90A. (Abst) 


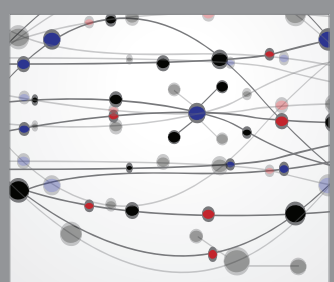

The Scientific World Journal
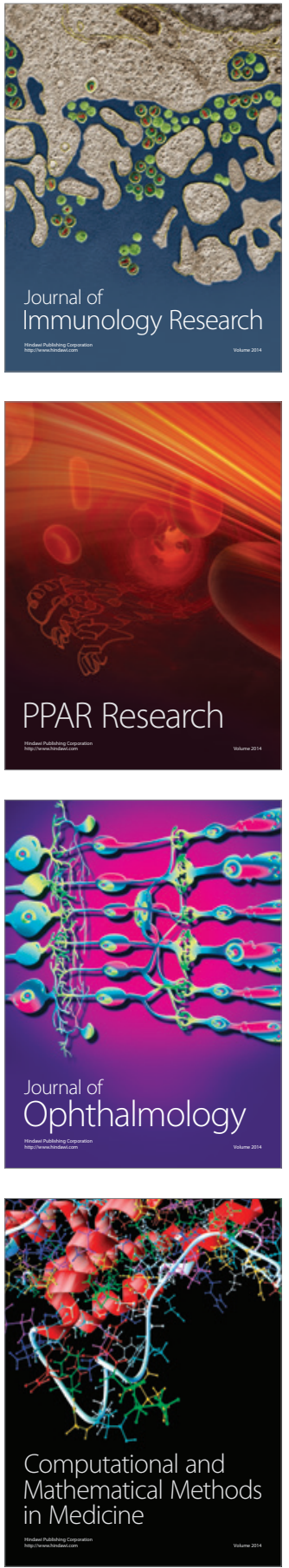

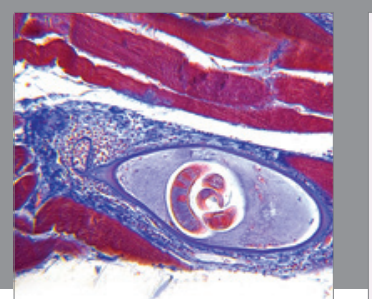

Gastroenterology Research and Practice

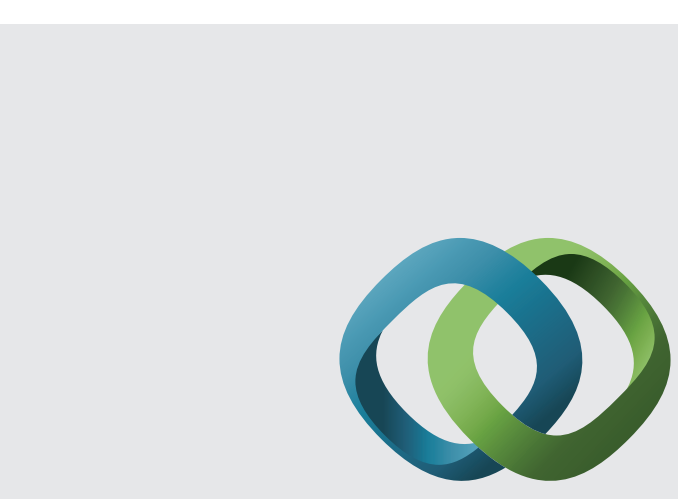

\section{Hindawi}

Submit your manuscripts at

http://www.hindawi.com
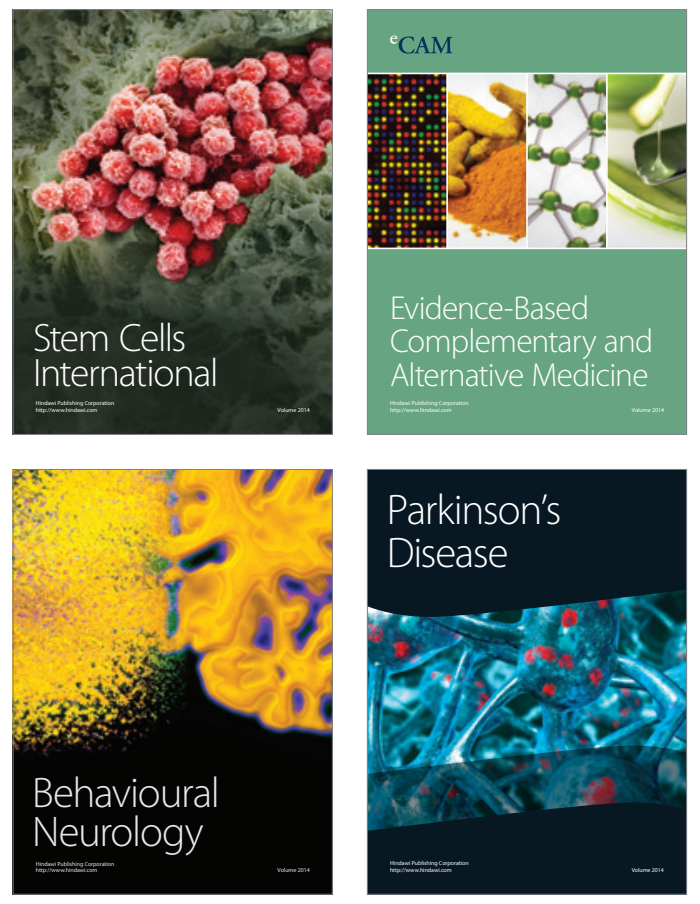
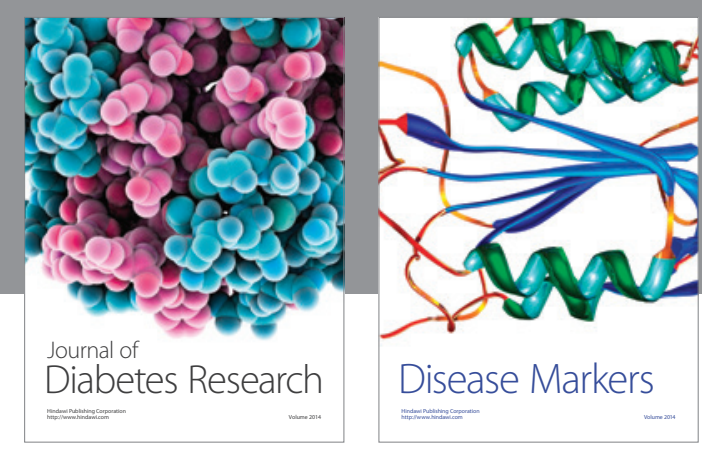

Disease Markers
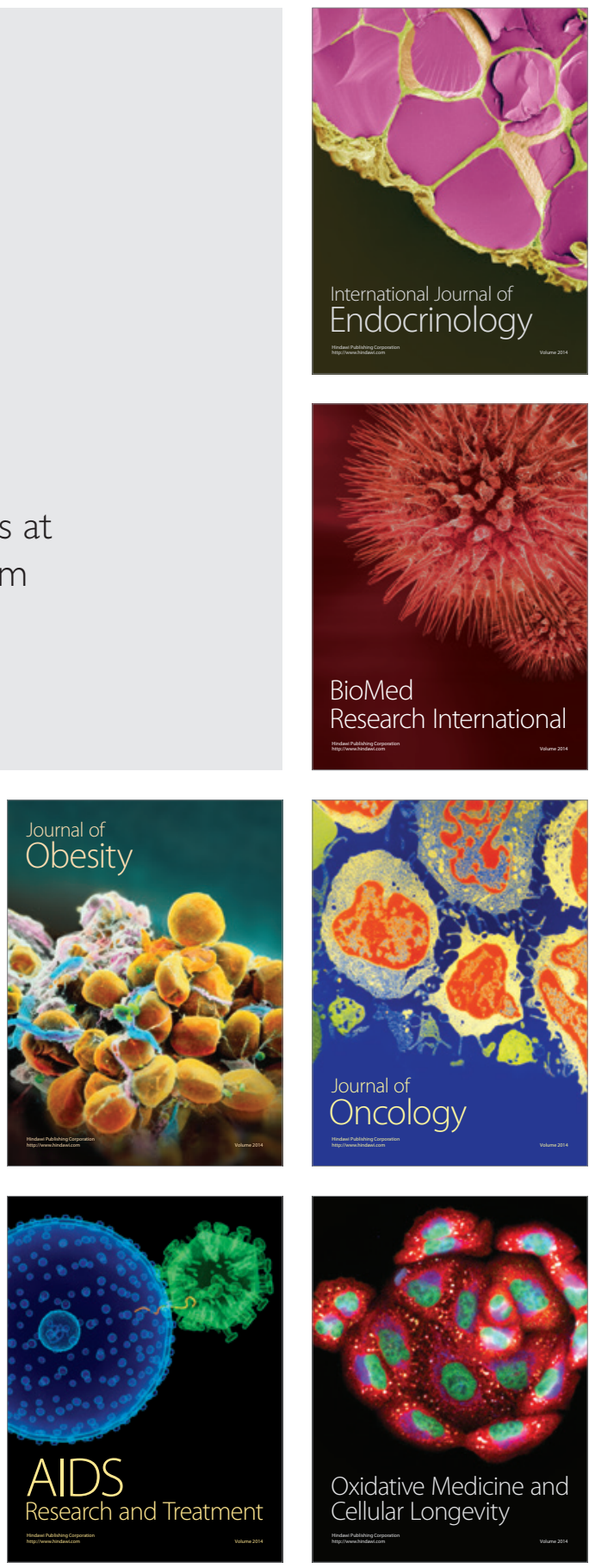